\title{
Kinetic Properties of Galactose Oxidase from Gibberella fujikuroi
}

\author{
Kazuo Aisaka, Takayuki UwaJima and Osamu Terada \\ Tokyo Research Laboratory, Kyowa Hakko Kogyo Co., \\ Machida-shi, Tokyo 194, Japan
}

Received September 13, 1983

\begin{abstract}
The kinetic properties of galactose oxidase of Gibberella fujikuroi were investigated. The enzyme oxidized D-galactose, 2-substituted D-galactoses, 2-epimer D-talose, and D-galactosecontaining oligosaccharides, but not other saccharides. The enzyme was highly specific for molecular oxygen as an electron acceptor. The enzyme gave a nonlinear Lineweaver-Burk plot when the oxidation rate at a variety of galactose concentrations was investigated. The data were well explained by the assumption that the enzyme has two binding sites for galactose. $K_{1}$ and $K_{2}$, which are the dissociation constants for the first and second bindings of galactose to the enzyme, were calculated to be $1.3 \mathrm{~mm}$ and $42 \mathrm{mM}$, respectively. The 'enzyme was mixedly inhibited by Dgalacturonic acid.
\end{abstract}

Galactose oxidase (EC 1.1.3.9) is an enzyme which catalyzes the oxidation of D-galactose to D-galactohexodialdose with the reduction of molecular oxygen to hydrogen peroxide. ${ }^{1)}$ In our previous studies, we reported that $G i b$ berella fujikuroi excretes significant amounts of galactose oxidase into the culture medium, ${ }^{2)}$ and also reported the purification and some properties of the enzyme. ${ }^{3)}$ The present paper describes the substrate specificity and kinetic properties of Gibberella galactose oxidase.

\section{MATERIALS AND METHODS}

Enzyme preparation. Galactose oxidase was purified from a culture filtrate of Gibberella fujikuroi according to the methods described previously. ${ }^{2,3)}$ The purified enzyme preparation had a specific activity of 3.3 units $/ \mathrm{mg}$ protein, and showed one major protein band of the enzyme and 2 or 3 other minor faint bands by silver staining after polyacrylamide gel electrophoresis.

Enzyme assay. Galactose oxidase activity was assayed by determining the hydrogen peroxide produced during oxidation of galactose with a 4-aminoantipyrine-phenolperoxidase system, according to the method described previously. $^{2)}$

Chemicals. D-Galactose was purchased from the
Nakarai Kagaku Co., Kyoto. Peroxidase from horseradish (Grade III, 100 units/mg solid) was a product of the Toyobo Co., Osaka. Other chemicals were the best commercial products available.

\section{RESULTS}

\section{Substrate specificity}

The substrate specificity was examined with various sugar substrates. In addition to Dgalactose, a number of D-galactose analogues were oxidized, as shown in Table I. 2-Substituted galactoses such as 2-deoxy-D-galactose, D-galactosamine, and $N$-acetyl-D-galactosamine, a 2-epimer such as D-talose, and galactosides were effectively oxidized. However, L-galactose, D-galactose-1-phosphate, and other isomeric D-aldohexoses were not oxidized at all. D-Galactose-containing di- and oligosaccharides such as melibiose, raffinose, and stachyose were oxidized at about the same rate as was D-galactose. Dihydroxyacetone was also a good substrate.

The effect of various acceptors on the activity was also examined. Molecular oxygen was the only effective acceptor for electrons, and other acceptors tested were completely ineffective (Table II). 
Table I. Substrate Specificity of Galactose OXIDASE IN THE OXIDATION OF Various Sugars

The rates of oxidation were determined with 20 munits of purified enzyme under the standard assay conditions, and were expressed as a percentage of that of D-galactose.

\begin{tabular}{|c|c|}
\hline Substrate & $\begin{array}{c}\text { Relative } \\
\text { activity } \\
(\%)\end{array}$ \\
\hline D-Galactose & 100 \\
\hline L-Galactose & 0 \\
\hline D-Galactono- $\gamma$-lactone & 0 \\
\hline D-Galacturonic acid & 0 \\
\hline Galactitol & 0 \\
\hline 2-Deoxy-D-galactose & 43 \\
\hline D-Galactosamine & 11 \\
\hline$N$-Acetyl-D-galactosamine & 60 \\
\hline D-Galactose-1-phosphate & 0 \\
\hline D-Galactose-6-phosphate & 0 \\
\hline Methyl- $\alpha$-D-galactopyranoside & 84 \\
\hline Methyl- $\beta$-D-galactopyranoside & 123 \\
\hline UDP-galactose & 6 \\
\hline D-Allose & 0 \\
\hline D-Altose & 0 \\
\hline D-Glucose & 0 \\
\hline D-Mannose & 0 \\
\hline D-Gulose & 0 \\
\hline D-Idose & 0 \\
\hline D-Talose & 52 \\
\hline D-Fructose & 1 \\
\hline Inositol & 0 \\
\hline Maltose & 0 \\
\hline Sucrose & 0 \\
\hline Lactose & 1 \\
\hline Melibiose & 68 \\
\hline Raffinose & 98 \\
\hline Stachyose & 79 \\
\hline Glycerol & 1 \\
\hline DL-Glyceraldehyde & 0 \\
\hline Dihydroxyacetone & 135 \\
\hline Dihydroxyacetone phosphate & 0 \\
\hline
\end{tabular}

\section{Kinetics}

The effect of galactose concentration in the range of 0.5 to $200 \mathrm{~mm}$ on the oxidation rate was examined. The substrate saturation curve showed a sigmoidal character at very low galactose concentrations, and the double reciprocal plot gave a downward convex curve, as shown in Fig. 1. From Hill's plot, ${ }^{4)}$ a value of 1.3 for $n$ (Hill coefficient) was obtained, though data not shown. This type of behavior has been termed substrate activation, and may be explained by a mechanism in which the substrate itself acts as a modifier. ${ }^{5)}$ Therefore, in order to account for the experimental data obtained here, the following assumptions were made:

1) Gibberella galactose oxidase has two binding sites for galactose, and the oxidation of galactose normally proceeds only when both of the two binding sites are occupied by galactose.

2) The two binding sites are qualitatively identical, and consequently which of the two sites is first occupied by galactose is decided by chance.

3) However, the first binding of galactose to the enzyme affects the second binding of galactose to the enzyme.

4) The other substrate, molecular oxygen, does not affect the bindings of galactose to the enzyme, and is not rate-limiting under the assay conditions used here.

The following scheme can be written based on these assumptions ${ }^{6,7)}$;

$$
E \stackrel{K_{1}}{\leftrightharpoons} \mathrm{ES} \stackrel{K_{2}}{\leftrightharpoons} \mathrm{ESS} \stackrel{k_{+5}}{\longrightarrow} \mathrm{ES}+\text { Products }
$$

where, $K_{1}$ stands for the dissociation constant in the first binding, and $K_{2}$ for the dissociation constant in the second binding $\left(K_{1} \neq K_{2}\right)$, as defined by the following equations:

$$
\begin{aligned}
& K_{1}=\frac{[\mathrm{E}][\mathrm{S}]}{[\mathrm{ES}]} \\
& K_{2}=\frac{[\mathrm{ES}][\mathrm{S}]}{[\mathrm{ESS}]}
\end{aligned}
$$

Rapid-equilibrium treatment leads to the following rate equation:

$$
v=k_{+5}[\mathrm{ESS}]=\frac{V[\mathrm{~S}]^{2}}{K_{1} K_{2}+K_{2}[\mathrm{~S}]+[\mathrm{S}]^{2}}
$$

Where $v$ is the oxidation rate of D-galactose. The following two cases were considered.

i) At high galactose concentrations where $[\mathrm{S}] \gg K_{1}$ holds, Eq. (4) becomes the MichaelisMenten type of equation as shown below:

$$
v=\frac{V[\mathrm{~S}]}{K_{2}+[\mathrm{S}]}
$$


Table II. Substrate Specificity of Galactose Oxidase in the Acceptors

The enzyme reaction was carried out in an evacuated Thunberg tube containing a mixture composed of $250 \mu \mathrm{mol}$ of galactose, $50 \mu \mathrm{mol}$ of TES- $\mathrm{NH}_{4} \mathrm{OH}$ buffer, $\mathrm{pH} 7: 0,50$ munits of purified enzyme, and each electron acceptor at the concentration specified in a total volume of $3 \mathrm{ml}$.

The reduction rate of each acceptor was determined by following the absorbance changes at the wavelengths indicated, and was expressed as a percentage of that of molecular oxygen, which was determined under the standard assay conditions.

\begin{tabular}{lccc}
\hline Electron acceptor & $\begin{array}{c}\text { Concentration } \\
(\mathrm{mm})\end{array}$ & $\begin{array}{c}\text { Wavelength } \\
\text { observed } \\
(\mathrm{nm})\end{array}$ & $\begin{array}{c}\text { Relative } \\
\text { activity } \\
(\%)\end{array}$ \\
\hline $\mathrm{O}_{2}$ & Dissolved $^{a}$ & & 100 \\
${\text { Cytochrome } c^{b}}_{\text {2,6-Dichlorophenolindophenol }}$ & 0.1 & 550 & 0 \\
2,6-Dichlorophenolindophenol & 0.1 & 600 & 0 \\
plus phenazine methosulfate & & & 0 \\
Ferricyanide & $0.1,1$ & 600 & 0 \\
Methylene blue & 1 & 420 & 0 \\
Nitro blue tetrazolium & 0.01 & 650 & 0 \\
NAD & 1 & 535 & 0 \\
NADP & 1 & 340 & 0
\end{tabular}

a In distilled water.

b Horse heart.

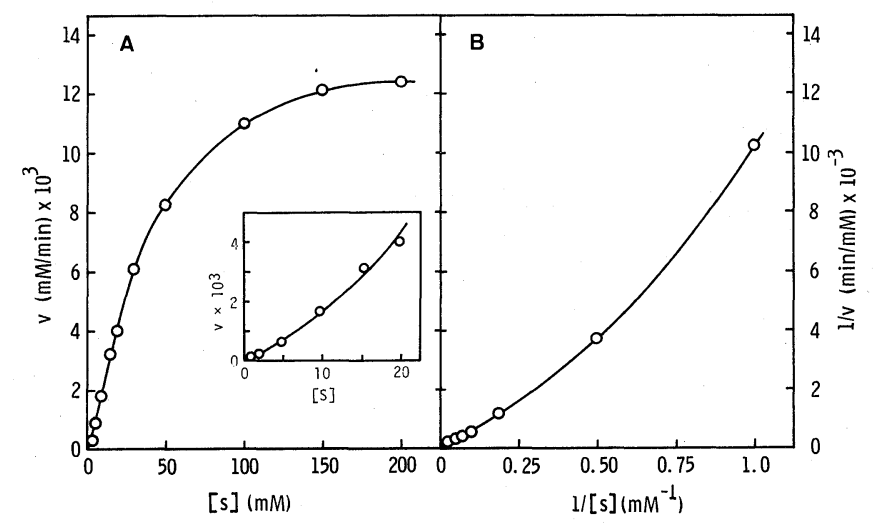

FIG. 1. Effect of D-Galactose Concentration on the Gibberella Galactose Oxidase Reaction.

A: The initial velocities $(v)$ were determined under the standard assay conditions except that varying concentrations of D-galactose were used. Reaction time was $5 \mathrm{~min}$ in the range of $15 \sim 200 \mathrm{~mm}$ galactose, and $60 \mathrm{~min}$ in the range of $1.0 \sim 10 \mathrm{~mm}$. The rate is expressed in $\mathrm{mm}$ per min. The insert shows the initial velocities in the range of $1.0 \sim 20 \mathrm{~mm}$.

B: The double reciprocal plot was obtained from the data of A.

This equation is transformed into:

$$
\frac{[\mathrm{S}]}{v}=\frac{1}{V}[\mathrm{~S}]+\frac{K_{2}}{V}
$$

The plot of $[\mathrm{S}] / v v s$. [S] gave a straight line at high galactose concentrations above $30 \mathrm{~mm}$, as shown in Fig. 2. The value of $K_{2}$, which is the intercept of the plot on the [S] axis, was $42 \mathrm{~mm}$.

ii) At low galactose concentrations where $[\mathrm{S}] \ll K_{2}$ holds, Eq. (4) becomes:

$$
v=\frac{V[\mathrm{~S}]^{2}}{K_{1} K_{2}+K_{2}[\mathrm{~S}]}
$$

This equation is transformed into: 


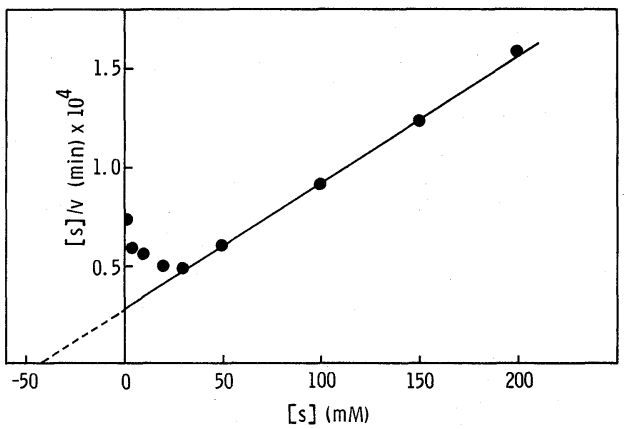

Fig. 2. [S] $/ v$ vs. [S] Plot in the Range of High Galactose Concentrations.

The data of Fig. 1 in the range of $30 \sim 200 \mathrm{~mm}$ galactose were plotted in the form of $[\mathbf{S}] / v$ vs. $[\mathbf{S}]$.

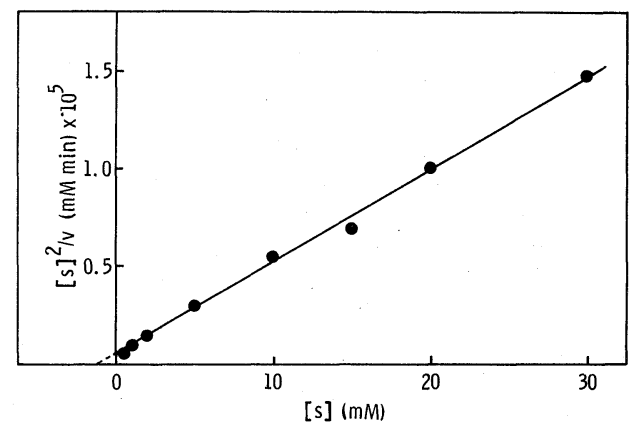

FIG. 3. $[\mathrm{S}]^{2} / v$ vs. $[\mathrm{S}]$ Plot in the Range of Low Galactose Concentrations.

The data of Fig. 1 in the range of $0.5 \sim 30 \mathrm{~mm}$ galactose were plotted in the form of $[\mathrm{S}]^{2} / v$ vs. [S].

$$
\frac{[\mathrm{S}]^{2}}{v}=\frac{K_{2}}{V}[\mathrm{~S}]+\frac{K_{1} K_{2}}{V}
$$

The plot of $[\mathrm{S}]^{2} / v$ vs. [S] gave a straight line, as shown in Fig. 3. The value of $K_{1}$, which is the intercept of the plot on the [S] axis, was $1.3 \mathrm{~mm}$.

The $K m$ value, which is [S] at which $V / 2$ is obtained, was calculated to be $43 \mathrm{~mm}$ from the relationship of

$$
K m=\left(K_{2}+\sqrt{K_{2}^{2}+4 K_{1} K_{2}}\right) / 2 .
$$

Thus, the results obtained indicate that Eq. (4), derived from the two binding sites model, is consistent with the kinetic data obtained experimentally with Gibberella galactose oxidase.
Table III. EfFect of Various Sugars on the ACTIVITY OF Galactose OXIDASE

The enzyme activities were determined with 20 munits of purified enzyme under the standard assay conditions containing the substrate, galactose $(250 \mu \mathrm{mol})$, and the various other sugar effectors $(250 \mu \mathrm{mol})$ indicated, and were expressed as a percentage of the activity with no addition.

\begin{tabular}{lc}
\hline \multicolumn{1}{c}{ Sugar added } & Relative activity $(\%)$ \\
\hline No addition & 100 \\
D-Galactono- $\gamma$-lactone & 76.3 \\
D-Galacturonic acid & 33.2 \\
Galactitol & 103 \\
D-Glucose & 99.4 \\
D-Mannose & 97.2 \\
D-Fructose & 87.5 \\
D-Fucose & 97.6 \\
Inositol & 101 \\
Lactose & 97.1 \\
Maltose & 104 \\
Sucrose & 105 \\
Glycerol & 102 \\
\hline
\end{tabular}

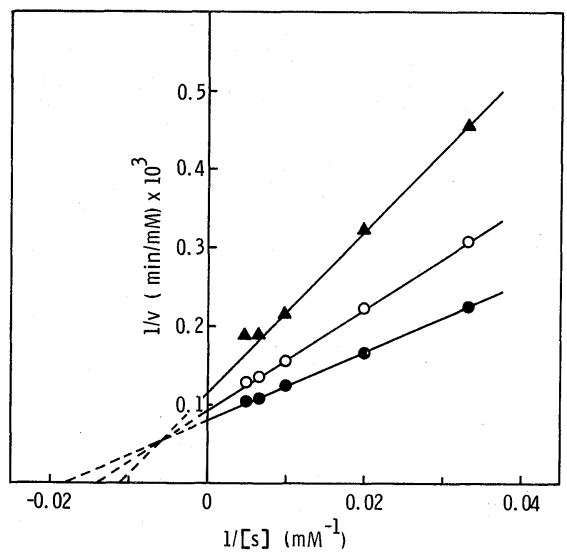

FIG. 4. Double Reciprocal Plots of the Inhibitory Effect of D-Galacturonic Acid on Galactose Oxidase.

The initial velocities were determined under the standard assay conditions except that varying concentrations of Dgalactose and D-galacturonic acid were used. DGalacturonic acid concentration $(\mathrm{mm}): 0,0 ; \bigcirc, 20 ; \mathbf{\Delta}$, 50 .

\section{Inhibition studies}

The effects of various sugars on the enzyme activity were examined. Galactose analogues such as D-galacturonic acid and D-galactono- $\gamma$ lactone inhibited the enzyme activity, but sugars having no galactose configuration did 

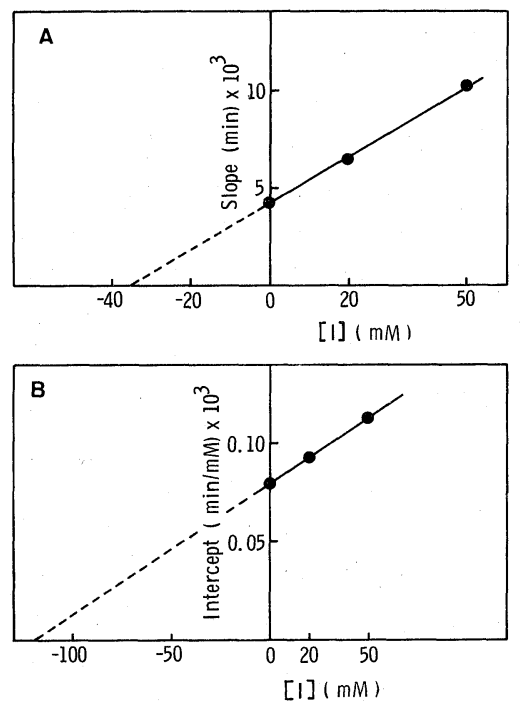

Fig. 5. Secondary Plots of the Slopes and Intercepts against D-Galacturonic Acid Concentration.

A: The slopes of the primary plots in Fig. 4 were replotted against the inhibitor concentration.

B: The intercepts of the primary plots in Fig. 4 were replotted against the inhibitor concentration.

not affect the enzyme activity (Table III). When the mode of inhibition was tested with
D-galacturonic acid, it mixedly inhibited the enzyme activity towards D-galactose, as shown in Fig. 4.

From this result, the following scheme was written $^{8)}$;

$$
\begin{aligned}
& \mathrm{E} \stackrel{K_{1}}{\leftrightharpoons} \mathrm{ES} \stackrel{K_{2}}{\leftrightharpoons} \mathrm{ESS} \stackrel{k_{+5}}{\longrightarrow} \mathrm{ES}+\text { Products } \\
& K i\left\|\quad K i^{\prime}\right\| \quad K i^{\prime \prime} \| \\
& \mathrm{EI} \underset{K_{1}{ }^{\prime}}{\rightleftharpoons} \mathrm{ESI} \underset{K_{2}{ }^{\prime}}{\rightleftharpoons} \mathrm{ESSI}
\end{aligned}
$$

where, $K i, K i^{\prime}$, and $K i^{\prime \prime}$ are the inhibition constants defined by the following equations:

$$
\begin{aligned}
K i & =\frac{[\mathrm{E}][\mathrm{I}]}{[\mathrm{EI}]} \\
K i^{\prime} & =\frac{[\mathrm{ES}][\mathrm{I}]}{[\mathrm{ESI}]} \\
K i^{\prime \prime} & =\frac{[\mathrm{ESS}][\mathrm{I}]}{[\mathrm{ESSI}]}
\end{aligned}
$$

Rapid-equilibrium treatment leads to the following rate eqation:

$$
v=\frac{V[\mathrm{~S}]^{2}}{\left(1+\frac{[\mathrm{I}]}{K i}\right) K_{1} K_{2}+\left(1+\frac{[\mathrm{I}]}{K i^{\prime}}\right) K_{2}[\mathrm{~S}]+\left(1+\frac{[\mathrm{I}]}{K i^{\prime \prime}}\right)[\mathrm{S}]^{2}}
$$

At high galactose concentrations where $[\mathrm{S}] \gg K_{1}$ holds, Eq. (13) becomes:

$$
v=\frac{V[\mathrm{~S}]}{\left(\left(1+\frac{[\mathrm{I}]}{K i^{\prime}}\right) K_{2}+\left(1+\frac{[\mathrm{I}]}{K i^{\prime \prime}}\right)[\mathrm{S}]\right.}
$$

From the secondary plots (Fig. 5), the inhibition constants, $K i^{\prime}$ and $K i^{\prime \prime}$, were calculated to be 36 and $110 \mathrm{~mm}$, respectively. From the relationship of $K_{2} / K_{2}{ }^{\prime}=K i^{\prime} / K i^{\prime \prime}, K_{2}{ }^{\prime}$ was calculated to be $127 \mathrm{~mm}$. However, the inhibitory effect ( $K i$ value) of D-galacturonic acid in the presence of low galactose concentrations could not be determined exactly because of experimental error.

\section{DISCUSSION}

The sugar substrate specificity of galactose oxidase of Polyporus circinatus (and/or Dactylium dendroides) is characterized as follows ${ }^{9 \sim 11)}$ :

1) The pyranose ring is important for the enzyme activity.

2) The galactose configuration at carbon 4 is essential, but the configuration at carbon 2 is not so critical.

3) The carbon 1 position need not be free, and the $\beta$-configuration is somewhat favored.

4) Oligosaccharides containing a galactose residue at the nonreducing end are oxidized more rapidly than is free galactose. The sugar substrate specificity of Gibberella galactose 
oxidase was essentially the same as that of galactose oxidase of Polyporus circinatus (and/or Dactylium dendroides), although oligosaccharides containing galactose residues were not necessarily oxidized more rapidly. These results suggest that galactose oxidases produced by these two microorganisms resemble each other closely in their catalytic properties, in spite of the differences in some of molecular properties described previously. ${ }^{3)}$ The structure of dihydroxyacetone seems to be apparently far from the galactose configuration, but may be in the proper orientation to be enzymatically oxidized. The kinetics of oxidation of dihydroxyacetone $\left(K_{1}=1.0 \mathrm{mM}\right.$ and $K_{2}=10 \mathrm{mM}$ ) was the same as those of the oxidation of galactose (data not shown), and hence both substrates seemed to be oxidized at the same catalytic sites of Gibberella galactose oxidase.

A concave curve of the Lineweaver-Burk plot was obtained when the oxidation rate of galactose by Gibberella galactose oxidase was examined by the use of a peroxidasechromogen assay system. In order to confirm the completeness of the coupling reaction, the reactivity of peroxidase to hydrogen peroxide was examined under the same assay conditions. The quinoneimine dye was immediately formed (within one minute), and the amount was a linear function of the concentration of hydrogen peroxide added in the range of 0.01 to $0.20 \mathrm{~mm}$ (data not shown). Therefore, it seemed that this concave curve of the Lineweaver-Burk plot was based on the kinetic properties of Gibberella galactose oxidase itself rather than on those of peroxidase. However, it may be necessary to confirm the results obtained here further by other assay methods. Similar curvatures are reported in many enzymes, including the saccharifying $\alpha$ amylase of Bacillus subtilis, ${ }^{12)}$ L-threonine deaminase of Clostridium tetanomorphum, ${ }^{13)}$ and deoxythymidine kinase of E. coli ${ }^{14)}$ Yoshida $e t$ $a l .{ }^{12)}$ accounted for this phenomenon by assuming that two kinds of substrate binding sites, one active and one activating, are present in the saccharifying $\alpha$-amylase of Bacillus sub- tilis, and that the binding of substrate to the activating site does not affect the binding at the active site, and vice versa. On the other hand, we could interpret the kinetic properties of Gibberella galactose oxidase by assuming the two identical galactose binding sites. Several different explanations of nonlinear plots may be possible. $^{5)}$ These are seldom kinetically distinguishable, and must be studied by other methods. Furthermore, the numbers of galactose binding sites and the binding constants may be estimated more correctly by the binding assay with ${ }^{14} \mathrm{C}$-labeled galactose. However, the simple model described here may be chosen as a working hypothesis up to that time.

It has not been reported that the galactose oxidase of Polyporus circinatus (and/or Dactylium dendroides) shows a nonlinear Lineweaver-Burk plot, although $\mathrm{Km}$ values for D-galactose varying from $2.8^{15}$ ) to $240 \mathrm{~mm}^{9}$ ) have been reported. Gibberella galactose oxidase showed a nonlinear Lineweaver-Burk plot when examined at a wide range of galactose concentrations, but showed a normal Lineweaver-Burk plot at high galactose concentrations, above $30 \mathrm{~mm}$. These results suggest that more detailed studies using a wide range of galactose concentrations are necessary for the kinetic elucidation of the galactose oxidase of Polyporus circinatus (and/or Dactylium dendroides).

Acknowledgment. The authors thank Miss Kyoko Kamezaki and Miss Kyoko Yagi for their excellent assistance.

\section{REFERENCES}

1) J. A. D. Cooper, W. Smith, M. Bacila and H. Medina, J. Biol. Chem., 234, 445 (1959).

2) K. Aisaka and O. Terada, Agric. Biol. Chem., 45, 2311 (1981).

3) K. Aisaka and O. Terada, Agric. Biol. Chem., 46, 1191 (1982).

4) A. V. Hill, Physiol. J., 40, 4 (1910).

5) C. Frieden, J. Biol. Chem., 239, 3522 (1964).

6) M. Dixon, E. C. Webb, C. J. R. Thorne and K. F. Tipton, "Enzymes," 3rd Ed., Longman, London, 1979, p. 47.

7) H. Chiba and E. Sugimoto, Tanpakushitsu Kakusan Koso, 11, 255 (1966). 
8) M. Dixon, E. C. Webb, C. J. R. Thorne and K. F. Tipton, "Enzymes," 3rd Ed., Longman, London, 1979, p. 332.

9) G. Avigad, D. Amaral, C. Asensio and B. L. Horecker, J. Biol. Chem., 237, 2736 (1962).

10) D. Amaral, F. Kelly-Falcoz and B. L. Horecker, "Methods in Enzymology," Vol. 9, ed. by S. P. Colowick and N. O. Kaplan, Academic Press Inc., New York, 1966, p. 87.

11) G. A. Hamilton, J. DeJersey and P. K. Adolf, "Oxidases and Related Redox System," Vol. 1, ed. by
T. E. King, H. S. Mason and M. Morrison, University Park Press, Baltimore, 1973, p. 103.

12) H. Yoshida, K. Hiromi and S. Ono, J. Biochem., 65, 741 (1969).

13) A. Nakazawa and O. Hayaishi, J. Biol. Chem., 242, 1146 (1967).

14) R. Okazaki and A. Kornberg, J. Biol. Chem., 239, 275 (1964).

15) G. C. Guilbault, P. J. Brignac, Jr. and M. Juneau, Analyt. Chem., 40, 1256 (1968). 